\title{
O USO DE MÍDIAS E TECNOLOGIAS DIGITAIS NAS AULAS REMOTAS DA EDUCAÇÃO BÁSICA DO MUNICÍPIO DA LAPA-PR, NO CONTEXTO PANDÊMICO DE 2020: DESAFIOS, LIMITAÇÕES, APRENDIZADOS E PROGRESSOS DOS PROFISSIONAIS DE EDUCAÇÃO PÚBLICA
}

\author{
Daiane Aparecida Dubinski Tavares ${ }^{1}$ \\ Juliane Simões Bolfe ${ }^{2}$
}

RESUMO: presente trabalho tem como objetivo investigar a percepção de professores sobre o uso de mídias e tecnologias digitais, bem como vantagens e desvantagens, as dificuldades e êxitos, em especial no período pandêmico de 2020. Para a realização do mesmo utilizou-se pesquisa biográfica e questionário destinado a vinte e sete professoras da rede de ensino básico do município da Lapa-Pr. O presente assunto é muito amplo, trazendo muitos questionamentos e possíveis estudos. Assim, optou-se por buscar conhecimento a respeito da importância do uso das tecnologias digitais em sala de aula, nas aulas remotas e o que isso acarretou no trabalho do educador. Observou-se a demanda por adequação diante da nova realidade e da necessidade de constante capacitação primordialmente no uso didático de tecnologias digitais e a importância da resiliência por parte desses profissionais. Os professores demonstraram grande superação enfrentando uma realidade desconhecida, adaptando o ensino presencial para o remoto e se reinventando.

Palavras- chaves: educação. Tecnologias. mídias sociais. pandemia.

\section{INTRODUÇÃO}

Todos os dias surgem novos desafios no campo da educação, principalmente quando básica e pública. No ano de 2020 um acontecimento de nível mundial abalou a educação, bem como todos os demais setores: a Pandemia de Covid-ı9 (doença causada pelo vírus SARS-CoV-2), diante o caos que se instalou devido à mesma, viu-se a necessidade do isolamento social. As escolas fecharam as portas, bem como o comércio e as casas também. Porém, como direito fundamental defendido pela Constituição Federal de

\footnotetext{
${ }^{1}$ Graduada em pedagogia (2016), especialista em Fundamentos para alfabetização e letramento e a psicopedagogia institucional (2020), especialista em EAD 4.0 (2021) pela Faculdade Educacional da Lapa-Fael. Pós-graduanda em Neuropsicopedagogia pela Faculdade Única. Neuroprendizagem. Neurociência aplicada à educação e Neurociência e o comportamento pela Faculdade Intervale. Neurociência e aprendizagem pelo grupo Zayn. E-mail: daidubinski@hotmail.com.

${ }^{2}$ Mestre em educação pela Universidade Tuiuti do Paraná (2009); doutoranda do programa de comunicação e linguagem da Universidade Tuiuti do Paraná. Professora e orientadora da Faculdade Educacional da Lapa.
} 
I988 e pelo Estatuto da Criança e do Adolescente (ECA) a educação teria que ir de encontro às crianças isoladas. Decretos direcionaram o rumo da mesma durante o isolamento e a forma de alcançar uma grande porcentagem dos alunos foi o uso da tecnologia digital, fazendo surgir à temática deste estudo: "As mídias e as tecnologias digitais na Educação Básica no contexto das aulas remotas durante a Pandemia de CovidI9 no ano de 2020".

Neste contexto, as questões que desencadearam a pesquisa foram: Como os professores fizeram uso das mídias e tecnologias digitais no processo de ensino aprendizagem durante o ano de 2020? Quais perspectivas e desafios foram encontrados? Qual aprendizado essa situação gerou aos profissionais da educação?

O objetivo da pesquisa foi investigar, por meio bibliográfico o uso das tecnologias digitais na educação e pesquisa quantitativa e qualitativa por meio de questionário online a percepção de professores de educação básica pública sobre o uso de mídias e tecnologias digitais, bem como vantagens e desvantagens, as dificuldades e êxitos.

Devido à singularidade da situação em que os professores se encontraram o presente trabalho traz relevância pessoal, profissional e social. No que diz respeito ao interesse pessoal porque no exercício da profissão em 2020, no ensino remoto de duas turmas de Pré I (crianças de 4 a 5 anos) percebeu-se a dificuldades em relação à formação pedagógica, tecnologia digital e a necessidade de capacitação contínua. Como relevância profissional este estudo contribuirá para promover uma análise em relação à prática docente diante das transformações que todos os dias se dão na sociedade, suas dificuldades e conquistas. Como relevância social contribuirá para a reflexão do uso de mídias e tecnologias digitais bem como suas causas e efeitos perante a educação na sociedade pandêmica de 2020 .

\section{DESENVOLVIMENTO}

Com o advento da internet no final do século XX, se fez necessário o avanço de aparelhos e mídias digitais que acompanhassem esse grande desenvolvimento. Em pleno 
século XXI o mercado disponibiliza celulares, tablets, computadores e uma infinidade de equipamentos de última geração para acompanhar o crescimento do uso da internet.

Diante desse mundo tecnológico as crianças; atuais alunos; vivem em uma realidade diferente que seus professores tiveram na infância, assim esses docentes precisam atender em suas salas de aulas educandos que por vezes ainda não foram letrados e alfabetizados, mas já convivem com muitas mídias e que se adaptam a elas mais facilmente que os professores. Andrade (2011, p.7) alega: "O desenvolvimento cognitivo do ser humano está sendo mediado por dispositivos tecnológicos onde as novas tecnologias da informação e comunicação estão ampliando o potencial humano". Vê-se então a necessidade da educação como um todo se reinventar para acompanhar esse desenvolvimento tecnológico.

\section{I INSTRUMENTO DE PESQUISA E DADOS DOS ENTREVISTADOS}

Para maior entendimento do assunto foi desenvolvido e aplicado um questionário online para vinte e sete professoras da Educação Básica do município da Lapa-Pr, sendo o mesmo documentado em forma quantitativa e qualitativa optando-se pela forma descritiva de dados para enriquecer o artigo.

Segundo Demo (2005, p.2I), "analisar significa decompor os dados obtidos em partes, desfiando uma a uma, em particular as tidas como mais importantes”. Assim, inicialmente foi questionado quanto à experiência destas profissionais e formação, pois é de grande importância aliar a prática ao conhecimento teórico, Antonello e Ruas (2005, p.39) alegam:

[...] que a aprendizagem baseada na ação funde deliberadamente a teoria com a prática e reconhece a interseção de formas explícitas e tácitas de saber em níveis individuais e coletivos [...] que a aprendizagem é adquirida por meio da prática e pode acontecer enquanto se trabalha, através das tarefas ou de relações, [...] que a estratégia de aprendizagem parece ser tão ou mais importante que os conteúdos específicos das disciplinas e seminários, pelo menos no que se refere ao desenvolvimento de certo tipo de competências.

Assim em relação à questão “Qual a sua formação?” cinco (I8,5\%) professoras alegaram possuir somente graduação em pedagogia e vinte e duas (81,5\%) alegaram já possuírem pós-graduação na área de educação. Questionadas em relação ao tempo de atuação na educação básica três (II,I\%) informaram que atuam de I a 3 anos, duas (7,4\%) 
atuam de 3 a 5 anos, cinco (18,5\%) atuam de 5 a 7 anos, uma (3,7\%) atua de 7 a ro anos e dezesseis $(59,3 \%)$ destas profissionais já atuam a mais de io anos na educação básica. Todas as professoras alegaram trabalhar remotamente no período pandêmico.

\title{
2.2 O USO DIDÁTICO DAS TECNOLOGIAS DIGITAIS EM SALA DE AULA
}

A inovação da comunicação através desses meios tem gerado oportunidades únicas como a comunicação por vídeo chamada, comunicação em tempo real, mensagens e áudios por aplicativos com pessoas em qualquer parte do mundo. Com essa nova realidade os professores precisam ser resilientes, se adaptando e buscando maneiras para inovar em sua prática pedagógica, visto que:

\begin{abstract}
As tecnologias como a internet e o computador são meios de comunicação, informação e expressão, e os educadores devem considerá-los como mecanismos para esses três meios, inclusive como uma forma de expressão entre eles e os alunos. $\mathrm{O}$ uso das tecnologias é iminente, e estão transformando as relações humanas em todas as suas dimensões: econômicas, sociais e no âmbito educacional não tem sido diferente. A apropriação desses meios de comunicação para construção do conhecimento vem mobilizando os educadores no sentido da seleção e utilização mais adequada dessas novas tecnologias. (ANDRADE, 2orr, p.7)
\end{abstract}

Diante de uma vasta gama de recursos, o educador precisa conhecer e avaliar o que pode ser desenvolvido, estimulado e que está acessível ao aluno nesse meio tecnológico. Para isso, o professor precisa estar em constante transformação, desenvolvendo habilidades através de formações e cursos para acompanhar o andamento e desenvolvimento do seu aluno, atuando de forma plena, unindo os conhecimentos adquiridos na sua formação, na prática de sala de aula e novos meios disponibilizados, uma vez que:

A integração entre a tecnologia digital com os recursos da telecomunicação, que originou a internet, evidenciou possibilidades de ampliar o acesso à educação, embora esse uso não implique práticas mais inovadoras e não represente mudanças nas concepções de conhecimento, ensino e aprendizagem ou nos papéis do aluno e do professor. No entanto, o fato de mudar o meio em que a educação e a comunicação entre alunos e professores se realizam traz mudanças ao ensino e à aprendizagem que precisam ser compreendidas ao tempo em que se analisam as potencialidades e limitações das tecnologias e linguagens empregadas para a mediação pedagógica e a aprendizagem dos alunos. (ALMEIDA, 2003, p. 329) 
$\mathrm{O}$ acesso a conteúdos da internet pode enriquecer grandemente o desenvolvimento dos planos de aula, práticas pedagógicas e conhecimento tanto do professor como do aluno, entretanto para isso, Rosa (2013) argumenta que o professor deve ter um conhecimento aprofundado dos conteúdos curriculares de ensino, bem como didáticas e meios de gerir o ensino/aprendizagem utilizando as novas tecnologias para beneficio da educação. Contudo ela exprime:

\begin{abstract}
As tecnologias se apresentam como ferramentas que permitem registrar, editar, combinar, manipular toda e qualquer informação, por qualquer meio, em qualquer lugar, a qualquer tempo. O seu uso nas práticas pedagógicas pode proporcionar a multiplicação de possibilidades de escolha, de interação. A mobilidade e a virtualização nos libertam dos espaços e tempos rígidos, previsíveis, determinados. Entretanto, os professores ainda encontram dificuldades para inserção das tecnologias no trabalho docente. (ROSA, 2013, p.221)
\end{abstract}

Essas ferramentas disponibilizam uma infinidade de possibilidades ao professor, desde a preparação até a aplicação de planos de aulas. $O$ uso da tecnologia favorece a interação do aluno que necessita de um mediador para compreender o seu próprio processo de ensino/aprendizagem. Porém, nem sempre a escola possui esses recursos e o professor por vezes não sabe usar aqueles disponibilizados.

Entretanto, é imprescindível um novo olhar para as tecnologias digitais, inovando na prática pedagógica, atualizando assim o contexto da educação, Cordeiro (2020, p.4) defende que

O uso das ferramentas tecnológicas na educação deve ser vista sob a ótica de uma nova metodologia de ensino, possibilitando a interação digital dos educandos com os conteúdos, isto é, o aluno passa a interagir com diversas ferramentas que o possibilitam a utilizar os seus esquemas mentais a partir do uso racional e mediado da informação.

Para isso é necessário um período de adaptação, a aprendizagem de "como e quando" usar uma tecnologia em aula leva certo tempo, bem como por em prática como explica Moran (2007, p.90):

O domínio pedagógico das tecnologias na escola é complexo e demorado. Os educadores costumam começar utilizando-as para melhorar o desempenho dentro dos padrões existentes. Mais tarde, animam-se a realizar algumas mudanças pontuais e, só depois de alguns anos, é que educadores e instituiç̃ôes são capazes de propor inovações, mudanças mais profundas em relação ao que vinham 
fazendo até então. Não basta ter acesso à tecnologia para ter o domínio pedagógico. Há um tempo grande entre conhecer, utilizar e modificar o processo.

Em relação aos meios tecnológicos utilizados em sala de aula antes do período pandêmico, os mais apontados foram vídeos, clips musicais, filmes sendo que vinte e três $(85,2 \%)$ professoras alegaram utilizar, seguidos de TV, computadores, celulares e tablets sendo utilizados por vinte e uma $(77,8 \%)$ professoras, músicas em formato Mp3 ou Mp4 indicados por $19(70,4 \%)$ das professoras e pesquisas na internet utilizadas por $15(55,6 \%)$ professoras, sendo possível optar por mais de uma resposta. Observou-se que os meios menos utilizados são os aplicativos de celulares que foram apontados apenas por nove $(33,3 \%)$ professoras e o PowerPoint indicado por uma (3,03\%) professora. Mencionados como maiores inibidores ao uso de tecnologias em sala de aula foram: falta de recursos tecnológicos, acesso ruim ou limitado de internet, a falta de disponibilidades destes recursos na escola.

\subsection{MÍDIAS E TECNOLOGIAS DIGITAIS UTILIZADAS NAS AULAS REMOTAS NO ANO DE 2020}

Com os alunos e professores isolados e as portas da escola fechadas, a educação precisou entrar nas casas dos alunos e os meios tecnológicos assumiram grande responsabilidade por isso. Como elucidam Moreira, Henriques e Barros (2020, p.2):

(...) a suspensão das atividades letivas presenciais, por todo o mundo, gerou a obrigatoriedade dos professores e estudantes migrarem para a realidade online, transferindo e transpondo metodologias e práticas pedagógicas típicas dos territórios físicos de aprendizagem, naquilo que tem sido designado por ensino remoto de emergência.

Se, em sala, a tecnologia se fazia importante, diante do isolamento social devido a Pandemia do Covid-ı9 (doença causada pelo vírus SARS-CoV-2) se tornou indispensável para o cumprimento do ano letivo em 2020. Assim sendo, defendida pelo Estatuto da Criança e Adolescente, Art. 53 da Lei 8.069 de 1990 "A criança e o adolescente têm direito à educação, visando o pleno desenvolvimento de sua pessoa, preparo para o exercício da cidadania e qualificação para o trabalho (...)" e ainda pelo Art. 205 da Constituição Federal de 1988: 
A educação, direto de todos e dever do Estado e da família, será promovida e incentivada com a colaboração da sociedade, visando ao pleno desenvolvimento da pessoa, seu preparo para o exercício da cidadania e sua qualificação para o trabalho. (BRASIL; 1988)

O ensino remoto foi implantado na tentativa de garantir esse direito aos alunos. Surgiu então a necessidade de adaptação da sociedade como um todo: pais, filhos e professores. As vinte e sete professoras alegaram continuar lecionando através do ensino remoto, porém ao serem questionadas em relação à formação acadêmica tê-las preparado para ministrar essas aulas apenas uma $(3,7 \%)$ alegou que sim, a formação acadêmica a preparou. Cinco $(18,5 \%)$ alegaram que a especialização em educação à distância as auxiliaram; treze $(48,1 \%)$ indicaram que em sua formação acadêmica inicial não houve embasamento para o ensino remoto e oito (29,6\%) declararam que pesquisaram por conta própria e fizeram cursos de capacitação para atender melhor os alunos.

Nesse contexto, preparar aula tornou-se um desafio e um aprendizado também. Silva (p.5) nos aponta que:

Para preparar uma aula mediada por tecnologias digitais, o professor deverá realizar os mesmos procedimentos de planejamento necessários para preparação de qualquer plano de aula. Selecionar conteúdos curriculares; definir os objetivos de ensino; descrever a metodologia adotada; identificar os recursos didáticos necessários e estabelecer a atividade para avaliação da aprendizagem. No processo de pesquisa que precede a preparação de qualquer aula, o professor incluirá em seu trabalho as informações necessárias sobre a tecnologia digital que será usada para mediar a aprendizagem, relatos de experiência de usos pedagógicos dessa tecnologia por outros professores, software (programa de computador) apropriado para a atividade que pretende propor, testes e experimentos para prever possíveis problemas durante a execução da aula. O processo de planejamento da aula, em si mesmo, já é formativo.

Dessa forma além de preparar os conteúdos o professor precisa ter conhecimento sobre a tecnologia que será usada em sua didática, bem como compreender se a mesma alcançará o seu aluno e servirá para o propósito estabelecido e resultará dentro dos objetivos definidos.

Questionados os meios de envio das atividades remotas (sendo possível mais de uma opção de resposta), vinte e sete (Ioo\%) professoras utilizaram o celular como recurso (aplicativos, chamadas e mensagens de texto). Juntamente com o celular: sete $(25,9 \%)$ 
utilizaram canal no "You Tube" (plataforma de compartilhamento de vídeos), três (II,I\%) usaram e-mail e duas $(7,4 \%)$ empregaram Classroom (ferramenta on-line gratuita para postagem de atividades) ou similares. Dentro da pesquisa realizada vinte e duas (81,5\%) dessas profissionais enviavam atividades impressas para os alunos que não possuíam meios tecnológicos para o acesso as aulas remotas.

Para o planejamento das aulas, inquirido os recursos utilizados (sendo possível mais de uma opção de resposta), vinte e cinco (92,6\%) professoras usaram vídeos educativos e/ou clips musicais, vinte e duas $(8 \mathrm{r}, 5 \%)$ buscaram atividades em sites educacionais, dezenove $(70,4 \%)$ utilizaram músicas, onze $(40,7 \%)$ utilizaram também conteúdos de blogs, sites de pesquisa e três (II,I\%) usaram podcasts (áudios em uma plataforma em que o ouvinte acessa o momento que desejar).

\subsection{DESAFIOS ENFRENTADOS PELOS PROFISSIONAIS DA EDUCAÇÃO MEDIANTE AS AULAS REMOTAS.}

No tocante às aulas remotas, além dos já citados problemas em relação ao uso de tecnologias em sala, os professores precisaram se adaptar rapidamente e buscar meios e recursos para auxiliar os alunos e pais, aprender a usar diversas tecnologias, buscar formas de gerenciar a "nova realidade" e se adaptar aos decretos emitidos para orientar a comunidade. Cordeiro (2020, p.6) aponta:

\footnotetext{
Professores que tinham pouco ou nenhum contato com tecnologia precisaram começar a planejar aulas mediadas por telas junto a seus coordenadores pedagógicos, ao mesmo tempo em que descobrem sobre o funcionamento de ferramentas tecnológicas. Com aulas online, surgiram novos desafios que não eram comuns nos encontros presenciais como problemas de conexão e engajamento dos alunos à distância.
}

Ainda segundo o autor (2020) a adaptação e criatividade dos professores a se ajustar a nova realidade foi surpreendente, direcionando uma revolução educacional, demonstrando que a tecnologia é oportuna e que é preciso estar apto ao progresso tecnológico.

Questionada qual maior dificuldade enfrentada pelo professor em relação às aulas no período de pandemia de 2020 , em pergunta aberta, a maior citada foi à falta de retorno por parte dos alunos sendo apontada por oito (8) professoras, seguida da falta de 
colaboração dos pais, apontada por sete (7) professoras e alunos que não dispunham de celulares ou computador e sem acesso a internet (fundamental para o uso dos aplicativos usados para envio de atividades) indicada por seis (6) professoras. Também indicados como dificuldades: a falta de equipamentos pelo próprio professor para melhor adaptar as aulas (tablets, tripés, editores de vídeo, etc), a adaptação com a tecnologia, a falta de contato em sala com os alunos, conseguir adequar as aulas, ensinar os pais a ensinarem os filhos e se superar. Segundo uma professora (2021): “A maior dificuldade foi estabelecer uma rotina de estudos com os alunos, cumprimento de combinados além da necessidade da utilização constante de atividades motivacionais visando garantir a qualidade deste acesso".

Cury (2020, p.I4-15) enfatiza que:

Ficam evidentes os limites de um ensino doméstico. Os pais ou tutores ou cuidadores, exceto os que são profissionais do magistério, não são profissionalizados, não foram preparados para tal situação. E, mesmo assim, nem todos os profissionalizados o são para a educação infantil e os anos iniciais do ensino fundamental.

Dessa maneira os pais enfrentam semelhantes dificuldades tornando-se "professores assistentes" dos filhos, com a falta de preparação muitas vezes não conseguem desempenhar esse papel. Muitos pais também apresentam dificuldades em relação aos recursos tecnológicos tornando imprescindível a ação do professor.

Spodek e Saracho, (1998, p.I67) afirmam: "Quando os pais iniciam uma parceria com a escola, o trabalho com as crianças pode ir além da sala de aula, e as aprendizagens na escola e em casa passam se complementar mutuamente". Mas para o êxito do aluno é fundamental a parceria família-escola.

Fiorentini e Lorenzato (2006, p.46) salientam que:

[...] parece haver uma crença, entre alguns responsáveis pelas políticas educacionais, de que as novas tecnologias da informação e comunicação são uma panaceia para solucionar os males da educação atual. [...] se, de um lado, pode ser considerado relativamente simples equipar as escolas com essas tecnologias, de outro, isso exige profissionais que saibam utilizá-las com eficácia na prática escolar.

Como se observa o relato das professoras descrito acima, não basta apenas o uso de tecnologias e didáticas diversas, se faz necessário também à capacitação dos profissionais 
da educação e o engajamento dos alunos e pais para uma educação de qualidade e transformação do mundo educacional.

\title{
2.5 O APRENDIZADO DOS PROFISSIONAIS DIANTE OS DESAFIOS IMPOSTOS PELA PANDEMIA DE COVID-19 EM 2020
}

Para acompanhar o momento e manter o direito a educação para os alunos, os professores precisaram desenvolver diversas habilidades, bem como enfrentar as dificuldades e aprender a conviver com a nova realidade de forma mais rápida que a população, se adequando aos novos termos e as aulas remotas. Cordeiro (2020, p. Io) lembra que:

\begin{abstract}
Vale ressaltar que nem todos os educadores brasileiros tiveram formação adequada para lidarem com essas novas ferramentas digitais, precisam reinventar e reaprender novas maneiras de ensinar e de aprender. Não obstante, esse tem sido um caminho que apesar de árduo, é essencial realizar na atual situação da educação brasileira.
\end{abstract}

Finalizando o questionário foi solicitado que as professoras descrevessem seu maior aprendizado no período da pandemia de covid-ı9 em 2020 em pergunta aberta. Sete (7) delas alegaram que aprenderam se atualizar e reinventar, cinco (5) apontaram o uso de tecnologias para ministrar aulas como maior aprendizado, três (3) indicaram a paciência, empatia e persistência. A compreensão, resiliência, importância do ensino presencial, a união com as famílias, uso de qualquer material de forma didática e adaptação de recursos também foram indicados como aprendizado nesse período.

Uma professora (2021) relatou: "Foram inúmeros os aprendizados, entre os quais podemos destacar: melhor uso da tecnologia, organização dos horários alternativos, otimização do tempo. E principalmente que o contato virtual ajuda, auxilia, mas não supre o contato real." Outra alega: “Acredito que o professor precisa estar sempre em constante aperfeiçoamento, principalmente com as novas tecnologias e novos métodos para mediar à aprendizagem de forma efetiva.”.

Destacou-se também a seguinte resposta: "Somos seres sociáveis, a saúde psicológica é muito importante também e preciso estar em constante aprendizado.” A observação foi pertinente, pois em um momento em que os cuidados com a saúde física 
está tão evidenciado, uma das professoras percebeu a importância da saúde psicológica. Como cita Cordeiro (2020, p.ro):

Ter em mente o momento de estresse ao qual os professores estão submetidos, por serem demandados a exercer uma função para a qual não têm preparo, e o seu papel em apoiar e manter o engajamento dos alunos são pontos fundamentais para a educação, sem necessariamente cobrar muito do desempenho acadêmico nesse momento.

Diante desse momento tão adverso os professores precisaram lidar com seus temores pessoais e profissionais perante $\mathrm{da}$ nova realidade, responder a urgente necessidade de adaptação da educação e trabalhar os temores de seus alunos e familiares destes.

\section{CONSIDERAÇÕES FINAIS}

A pandemia não só exigiu o isolamento social como evidenciou a necessidade de transformação no meio educacional. Observou-se que no período pandêmico de 2020 os professores da educação básica do município da Lapa-Pr, precisaram se capacitar, reinventar e buscar novas habilidades em um curto período de tempo para fazerem uso das mídias e tecnologias digitais no processo de ensino aprendizagem que foram de suma importância no campo da educação.

O envio de atividade por meios virtuais possibilitou o acesso dos alunos à educação, mas também levou os professores a buscar novas estratégias de ensino, novas didáticas, maior capacitação e enxergar possibilidades através das tecnologias bem como perceber a importância da comunicação e união com a família.

Muitas das perspectivas dos professores foram frustradas ao se deparar com desafios por vezes que não estavam em sua alçada resolver, como por exemplo, a falta de equipamentos para aperfeiçoar as aulas ou mesmo a falta deles por parte dos alunos para recebê-las e em determinados casos a falta de engajamento familiar, ainda assim estes profissionais utilizaram outros meios como citado na pesquisa (atividades impressas e atividades motivacionais) para alcançar todos os alunos.

Os professores demonstraram que apesar de não estarem preparados para $o$ isolamento social, bem como toda a sociedade não estava, aceitaram os desafios impostos e 
buscaram desempenhar seu papel da melhor forma possível e cumprir sua missão de ensinar e aprender.

\section{REFERÊNCIAS}

ALMEIDA, M.E.B. Educação à distância na internet: abordagens e contribuições dos ambientes digitais de aprendizagem. Pontifícia Universidade Católica de São Paulo. Educação e Pesquisa, São Paulo, v.29, n.2, p. 327-340, jul./dez. 2003 329. Disponível em: http://www.scielo.br/pdf/ep/v29n2/aiov29n2.pdf. Acesso em: 13/o2/202I

ANDRADE, A.P.R. O uso das tecnologias da Educação: computador e internet. Brasília, 20II. (Monografia apresentada como trabalho de conclusão do Curso de Biologia da Universidade Estadual de Goiás) Disponível em https://bdm.unb.br/bitstream/10483/1770/1/20II_AnaPaulaRochadeAndrade.pdf Acesso em Io/o2/2021

ANTONELLO, C.S.; RUAS, R. Formação Gerencial: Pós-graduação Lato Sensu e o Papel das Comunidades de Prática. RAC, v. 9, n. 2, Abr./Jun. 2005.

BRASIL. Constituição (1988). Constituição da República Federativa do Brasil. Brasília, DF: Senado Federal: Centro Gráfico, 1988.

BRASIL. Lei no 8.069, de 13 de julho de 1990. Dispõe sobre o Estatuto da Criança e Adolescente e dá outras providências. Brasília, DF: Senado Federal: Centro Gráfico, I99o.

CORDEIRO, K. M. A. O Impacto da Pandemia na Educação: A Utilização da Tecnologia como Ferramenta de Ensino. 2020. Disponível em: http://idaam.sitew orks.com.br/jspui/bitstream/prefix/ı157/r/O\%2oIMPACTO\%2oDA\% 2оPANDEMIA\%2。NA\%2。EDUCA\%C3\%87\%C3\%83 O\%20A\%20UTILIZA\%C3\%87\%C3 $\% 83 \mathrm{O} \% 20 \mathrm{DA} \% 20$ TECNOLOGIA\%20COMO\%20FERRAMENTA\%2oDE\%20ENSINO. pdf Acesso em: io/o2/202I

CURY, Carlos Roberto Jamil. EDUCAÇÃO ESCOLAR E PANDEMIA. Pedagogia em Ação, Belo Horizonte, v.I3, n. I (I sem. 2020) - ISSN 2175-7003. Disponível em: http://periodicos.pucminas.br/index.php/pedagogiacao/article/download/23749/r676r Acesso em: 26/02/2021

DEMO, Pedro. Metodologia da Investigação em Educação. Curitiba: Ibepex, 2005.

FIORENTINI, Dario; LORENZATO, Sergio. Investigação em Educação Matemática: percursos teóricos e metodológicos. Campinas, SP: Autores Associados, 2006.

MORAN, José Manuel. A Educação que desejamos: novos desafios e como chegar lá. Campinas, SP: Papirus, 2007. 
MOREIRA, J. A., HENRIQUES, S., BARROS, D. (2020). Transitando de um ensino remoto emergencial para uma educação digital em rede, em tempos de pandemia. Dialogia, 34, 351-364 disponível em: https://repositorioaberto.uab.pt/handle/10400.2/9756 Acesso em I2/02/2021

ROSA. R. Trabalho docente: dificuldades apontadas pelos professores no uso das tecnologias. V. I, n.I, p. 214-227, 2013. Disponível em: http://revistas.uniube.br/index.php/anais/article/view/710/1007 Acesso: I8/02/202I

SILVA; Lebiam Tamar Gomes. PENSAR A EDUCAÇÃO MEDIADA POR TECNOLOGIAS DIGITAIS. Disponível em: https://www.google.com/search?q=uso+de+tecnologias+digitais+na+educa $\% \mathrm{C}_{3} \% \mathrm{~A}_{7} \% \mathrm{C}_{3}$ $\%$ A3o\&oq=uso + de+tecnologia + di\&aqs =chrome.I.69i57joiz2i3oj69i6rl2.23239joj7\&sourceid=c hrome\&ie $=U T F-8 \#$ Acesso em: 19/02/2021

SPODEK, Bernard; SARACHO, Olívia N. Ensinando crianças de 3 a 8 anos. Porto Alegre: ArtMed, 1998. 